\title{
Helmut Mehrer 65 Years
}

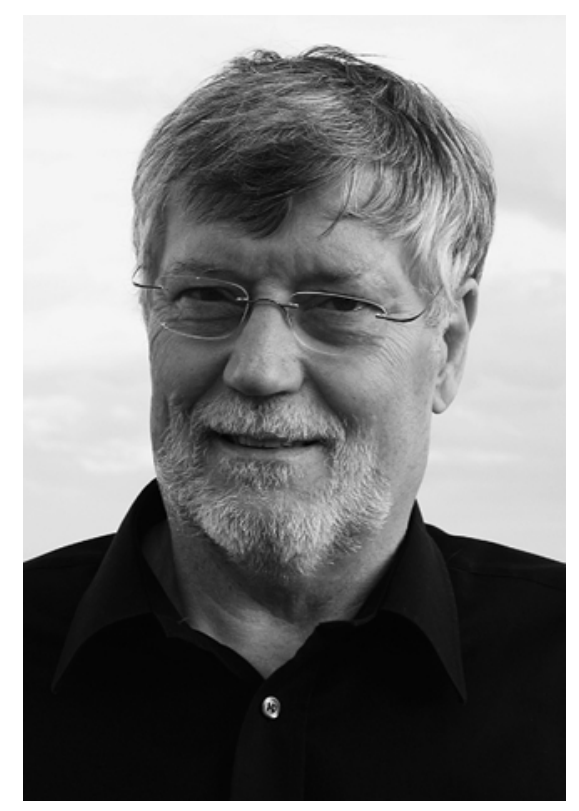

$\mathrm{O}$ October 22, 2004 Prof. Dr. rer. nat. Helmut Mehrer celebrates his 65 th birthday. On this occasion the present edition of the 'Zeitschrift für Metallkunde' is dedicated to him. All authors who submitted an article to this edition and also those colleagues and friends who could not contribute express their admiration and congratulations for the valuable work that Prof. Mehrer has done in the field of solid state diffusion.

Professor Dr. Helmut Mehrer was born in HeilbronnKlingenberg. After attending the primary school in Heilbronn-Klingenberg and the comprehensive secondary school (Robert Mayer-Gymnasium) in Heilbronn he decided 1958 to do first a practical training at the company AUDI-NSU in Neckarsulm before he studied physics at the University of Stuttgart from 1959 to 1965. During his diploma time he received a fellowship from the "Studienstiftung des Deutschen Volkes" which offered him the opportunity to leave Stuttgart for some time for studying physics at the ETH Zürich. In the year 1965 he finished under the guidance of Prof. Dr. H. Kronmüller his diploma thesis on the recovery of nickel after neutron irradiation and plastic deformation at the University Stuttgart. The following years he focused on correlation effects and reactions of point defects in crystals and was awarded a PhD in 1968 for his doctoral research which he performed under Prof. Dr. A. Seeger at the Max-Planck-Institut für Metallforschung in Stuttgart. He remained in Stuttgart from this time right up until 1984. During his Stuttgart time he received in 1973 the postdoctoral lecture qualification (habilitation) for Physics and became associate Professor in 1976. Despite being offered a full professorship at the University of Kassel he decided in favour of the Westfälische-Wilhelms-Universität Münster in 1984. As successor of Prof. Dr. Theodor Heumann he became director of the Institut für Metallforschung which is now called Institut für Materialphysik. From 1984 till today he spent several months as

guest professor at the California Institute of Technology in Pasadena and at the University of Debrecen in Hungary where he gave his interesting lectures on diffusion in solids. He served as Dean of the Fachbereich Physik at the University of Münster from 1990 to 1991. In 1995 he received the Werner-Köster-Preis from the DGM for the best article in the Journal of Zeitschrift für Metallkunde. Since 2000 Helmut Mehrer is member and vice speaker of the collaborative research center 458 on "ionic motion in materials with disordered structures - from elementary steps to macroscopic transport" of the Deutsche Forschungsgemeinschaft (DFG). He participated in the Priority Programmes "Quasicrystals" and "Undercooled Melts" of the DFG.

Under the supervision of Helmut Mehrer research was performed on diffusion in a wide class of material systems in order to determine the atomic mechanisms of diffusion and the properties of the point defects involved. Beside metallic materials such as $\mathrm{Fe}, \mathrm{Al}, \mathrm{Nb}, \mathrm{Fe}-\mathrm{Al}, \mathrm{Fe}-\mathrm{Si}, \mathrm{Mg}-\mathrm{Al}$, $\mathrm{Mo}-\mathrm{Si}$ and $\mathrm{Co}-\mathrm{Nb}$ alloys, just to name a few, also elemental and compound semiconductors, ion conducting glasses and new material systems such as bulk metallic glasses and quasicrystals were investigated. All studies significantly contribute to the good reputation of the Institut für Materialphysik which under his guidance became one of the leading contributors in the world to reliable solid state diffusion data. During his scientific career Prof. Mehrer was author or co-author of about 240 papers which were published in international scientific journals. He was very successful in fundraising which finds its expression in about 40 research projects supported by the DFG, two BMBF projects, and two GIF (German Israel Foundation for the Promotion of Science) projects. He supervised 62 diploma and 28 doctoral theses and received numerous invitations to national and international conferences. Prof. Mehrer is member of the editorial board of "Defect and Diffusion 
Forum" and "Materials Transactions" and was editor of the Landoldt-Börnstein on "Diffusion in Solid Metals and Alloys" (1990) and of the conference proceedings "Diffusion in Materials" (Scitec Publ. 1997). His cooperation in a number of international committees responsible for conferences such as "Diffusion in Materials" (DIMAT) and last but not least his organisation of DIMAT-96 in Nordkirchen are further evidence of his scientific reputation.

The 20 years of research of Prof. Mehrer in Münster were devoted to metallic materials (intermetallic compounds, silicides, quasicrystals, and metallic glasses) and semiconductors (silicon, germanium, group III-V compounds). His work focussed on accurate experiments to measure the diffusion of self- and foreign-atoms in solids. Numerous diffusion studies by means of radioactive isotopes and spreading resistance methods were conducted in the laboratory of his institute which has evolved to one of the worldwide largest diffusion laboratories. From 1999 on Prof. Mehrer included inorganic glasses in his research by studying with radiotracer diffusion and impedance spectroscopy the ion conductivity in borate and silicate glasses. Scientists from varies countries (Argentine, Czech and Slovak republic, Greek, Hungary, Israel, Japan, Korea, Russia, Ukraine) with a research fellowship from the Alexander von Humboldt Foundation or from the Deutscher Akademischer Austauschdienst (DAAD) worked at the institute and contributed to its scientific reputation.

During his scientific career of almost 37 years Prof. Mehrer was engaged not only in the research but also in administration and teaching. Since his appointment in 1984 until today he served as director of the Institut für Materialphysik. Already in Stuttgart he gave several lectures on solid state physics, defects in crystals but also lectures on basic physics such as continuum mechanics and statistical thermodynamics. From this early teaching experience he could benefit after he moved to Münster. There he gave lectures on solid state physics, materials science, and special courses on diffusion in solids, phase transitions in solids, and amorphous materials which motivated many students to prepare their diploma and/or doctoral thesis in solid state physics at the institute. His lectures were and are characterized by the clarity of presentation and the well-balanced mixture of theory and experiment. This concept also has gone down well for student with physics as subsidiary subject (students of medicine, biology and pharmacy). They very much enjoyed the basic physics demonstrated by numerous experiments.

All friends and colleagues thank Prof. Dr. Helmut Mehrer for his scientific and administrative engagement. We all hope that the next generation of solid state physicists will also profit from his professionalism in the presentation of physics. In this respect we are looking forward to the comprehensive textbook on "Diffusion in Solid Matter" which certainly will form a set book for diffusion and stimulate young students to enter the exciting world of materials science. On behalf of all guests who visited the Institute and Mehrer's home I also would like to thank Helmut Mehrer and in particular his wife Karin for their warm hospitality.

Hartmut Bracht, Münster 